\section{$2 \mathrm{I} 2$}

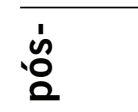

Figura 1: Auditório Ariosto Mila - Abertura do VIII ENEPEA Crédito: Autor
VIII ENEPEA - ENCONTRO NACIONAL DE ENSINO DE PAISAGISMO EM ESCOLAS DE ARQUITETURA E URBANISMO NO BRASIL - FAUUSP

\section{Silvio Soares Macedo}

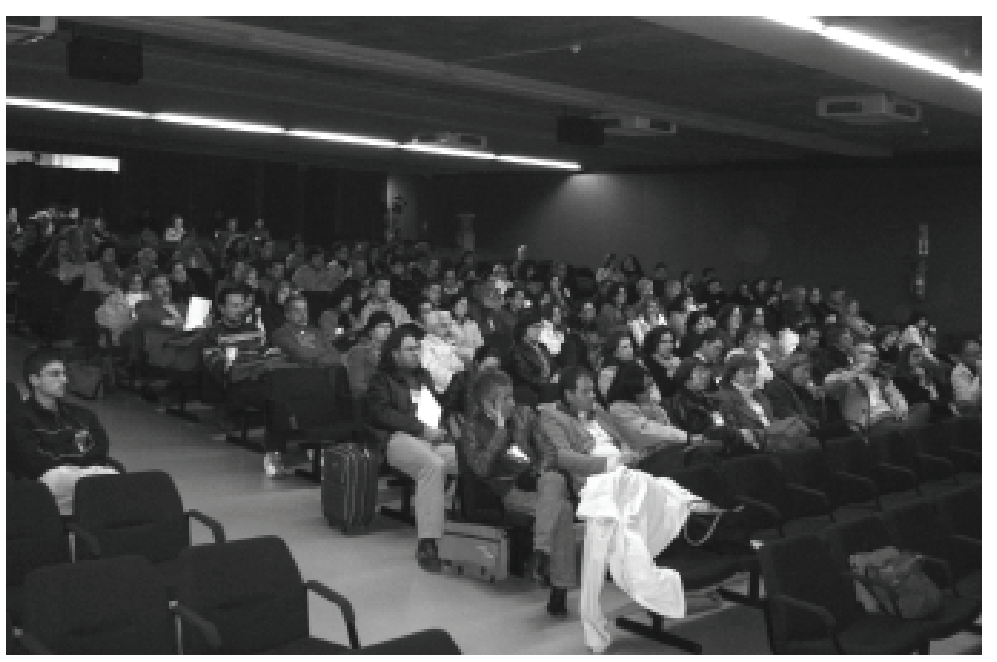

O VIII ENEPEA, realizado no período de 6 a 10 de setembro, seguiu perfeitamente seu programa, congregando, entre professores, pesquisadores e estudantes de graduação e pós-graduação de todo o país, 209 pessoas nas instalações da Faculdade de Arquitetura e Urbanismo da Universidade de São Paulo (FAUUSP).

Como resultado desse evento conseguiu-se estabelecer o "estado da arte" do ensino e da pesquisa em paisagismo no país, tanto em função da apresentação de trabalhos como em função das mesas-redondas, conferências e apresentações de trabalho individual e exposição de pôsteres.

Tivemos como resultados gerais:

1 - 0 entendimento que o ensino de paisagismo, em um dos três eixos (teoria, história e projeto), nas escolas de arquitetura e urbanismo no Brasil, é um fato que, apesar de obrigatório, está longe de estar consolidado, pois ainda que as diretrizes curriculares do Ministério da Educação e Cultura (MEC) indiquem essa obrigatoriedade, na realidade, a implementação de tais especificações não está sendo feita na maioria das quase 200 escolas do país, devido aos seguintes fatos:

a) Há falta de corpo docente preparado para tal;

b) há ausência de condições políticas dentro de muitos cursos para a existência de disciplinas individuais específicas, sendo o assunto tratado dentro das chamadas integrações ou disciplinas conjuntas de Arquitetura, Urbanismo e Paisagismo, ou seja, o paisagismo, quando existe, formaliza-se como um assunto complementar às outras duas áreas de conhecimento; 
c) os docentes existentes têm dificuldades em criar disciplinas de Paisagismo, pois necessitam, além de atender às demandas do MEC, fornecer aos futuros arquitetos e urbanistas fundamentos mínimos sobre o assunto, que habilitem os futuros profissionais a trabalharem de maneira ética e responsável sobre as questões paisagísticas nacionais, pelo menos no que diz respeito ao escopo das atividades do arquiteto e urbanista.

2 - A constatação da evolução expressiva do ensino em algumas escolas, todas vinculadas a instituições de porte, tais como a USP, UFSC e UFPe, que se tornaram centros de referência para as demais escolas.

3 - A introdução de novos conteúdos nessas e em outras escolas - como o planejamento da paisagem; de novos procedimentos de ensino e o início de trabalhos com a comunidade por parte de professores e alunos das disciplinas específicas de Paisagismo.

4 - A gradual mudança de objeto das disciplinas de Paisagismo, que se desloca dos jardins e áreas verdes genéricas para o espaço livre, elemento estrutural na organização da paisagem urbana e na paisagem em geral - no caso, os espaços livres de urbanização e de edificação. Esse redirecionamento torna mais consistente e estrutural o papel da disciplina Paisagismo não somente dentro das escolas de arquitetura, mas também para a sociedade em geral.

5 - A revelação do avanço e da consolidação da pesquisa em paisagismo no país, com o aumento das teses e dissertações, das iniciações científicas e o aumento, ainda pequeno, mas expressivo, dos trabalhos de pós-doutorado mostrados pelo número de trabalhos apresentados no VIII ENEPEA, a maioria derivada de atividades de pesquisa. Além disso, a qualidade das discussões desse evento, em todas as mesas e sessões, foi bem maior que nos demais encontros, mostrando um amadurecimento dos trabalhos apresentados e, portanto, dos pesquisadores, e um aumento do interesse do público pelo assunto.

6 - 0 início de atividades junto da comunidade por parte de professores e alunos, refletidos em diversos trabalhos, ainda que em pequeno número, tendo como objeto questões ambientais e paisagísticas.

7 - A apuração da necessidade de estabelecer-se os conteúdos necessários para o ensino do paisagismo, tanto nas escolas de arquitetura e urbanismo como em outras escolas, de modo a formar profissionais que tenham condições de enfrentar as questões paisagísticas e ambientais nacionais. No caso, entende-se existir um conhecimento acumulado significativo nesses últimos anos, em especial a partir da década de 1990, para tal, advindo especialmente da consolidação da pesquisa na área.

8 - A verificação da necessidade de estabelecer-se redes nacionais de pesquisa em paisagismo, para se estimular a troca de informações dos resultados de pesquisa nos diversos pontos do território nacional.

O encontro terminou em uma plenária na qual foram levantadas as preocupações e as questões acima, e decidiu-se que essas serão aprofundadas no próximo evento, a ser realizado na cidade de Curitiba, na Universidade Federal do Paraná (UFPR), pelo dr. Paulo Chiesa, tendo como referência as palavras "fronteiras, abrangente e instigante" e como objetivos mais específicos o ensino e seus conteúdos e a pesquisa no país e seus resultados. 


\section{ConferênCIAS}

Foram seis, cada uma com um objetivo claro, ministradas por seis importantes figuras do paisagismo, três delas expoentes nacionais: Miranda Magnoli, Rosa Kliass e Paulo Pellegrino, este um dos mais importantes teóricos e pesquisadores do planejamento paisagístico no Brasil. Além desses, tivemos a participação dos paisagistas e professores Sonia Berjman, Nathaniel Cormier e German Cruz, todos proferindo palestras especialmente encomendadas pela comissão científica do evento, de modo a contribuir no conhecimento do paisagismo para todos os congressistas. As palestras tiveram o seguinte teor:

Miranda Magnoli: "Paisagismo XXI... Conhecimento e Ação" - realizada na abertura do encontro; objetivou a introdução dos últimos conceitos e preocupações da professora sobre paisagem e paisagismo, deixando evidente 0 objeto central do paisagismo - no caso o espaço livre - e avançando mais sobre o novo desenho que se configura da paisagem urbana brasileira, não mais tão compacta e contínua como no passado recente. A palestra posterior, de Nestor Goulart Reis Filho, de acordo com a programação, foi, na realidade, uma homenagem à professora por seus anos de pesquisa e ensino, pela criação da área de Paisagismo na FAUUSP e pela definição dos conceitos básicos do paisagismo nacional. Na oportunidade, foi lançada pela FAUUSP uma edição especial da revista Paisagem e Ambiente - Ensaios sobre a obra de Miranda, contendo seus principais textos e reflexões; essa foi distribuída a todos os participantes do ENEPEA, como documento especial e oficial do evento.

Sonia Berjman: "Una Mirada al Paisagismo del Cono Sur Americano" - que trouxe, no início dos trabalhos de quinta-feira, uma visão geral sobre o desenvolvimento do paisagismo na Argentina, Uruguai, Paraguai e Chile, do século XIX aos nossos dias. O paisagismo, nos países de língua hispânica, é praticamente desconhecido no Brasil - a não ser pelos poucos conhecedores da extensa obra escrita da professora - e sua vinda teve como objetivo principal fornecer informações básicas sobre a matéria para um público diretamente interessado.

Figura 2: Conferência Paisagismo XXI Conhecimento e Ação, com a Profa. Dra. Miranda Martinelli Magnoli Crédito: Autor

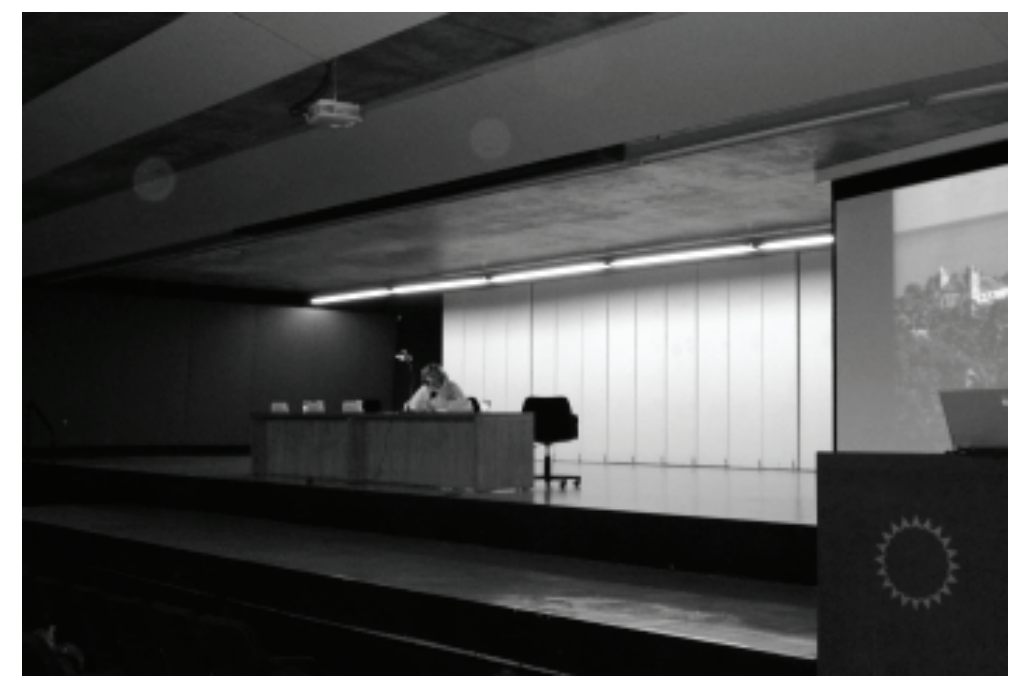

PÓS N.2I - SÃO PAULO • JUNHO 2007 
Rosa G. Kliass: "Da Responsabilidade do Profissional no Desenvolvimento da Formação do Arquiteto Paisagista" - por meio de sua trajetória profissional, a paisagista expôs uma série de princípios e posturas éticas que devem nortear a conceituação de projetos paisagísticos, seja no âmbito público, seja no privado.

Germán T. Cruz: "Teaching to See + Feel + Hear + Understand" - uma introdução de questões relativas ao ensino e ao pensar do projeto paisagístico. A palestra teve como finalidade trazer à platéia posturas de ensino e projeto contemporâneas desenvolvidas nos Estados Unidos, o país no qual teve origem o paisagismo como conhecemos hoje, respaldadas pelo conhecimento do professor, um expert no assunto, que em 2005 esteve no Brasil e na FAUUSP como professor convidado para o curso de capacitação de professores, organizado pela International Federation of Landscape Architecture (IFLA) e pela Fundação para a Pesquisa Ambiental (Fupam), ministrando disciplinas de projeto paisagístico.

Paulo R. Pellegrino: "Ecologia e Projeto: Referências para o Ensino" professor especialmente convidado, uma das maiores autoridades no país sobre o assunto, discorreu a respeito de conceitos básicos e de vanguarda para 0 desenvolvimento do paisagismo nacional, servindo ainda de referência e base de entendimento da palestra seguinte, de Nathaniel Cormier. Essa quinta e última conferência teve como objetivo central trazer novas técnicas e posturas do planejamento paisagístico e ambiental, exemplificadas em um conjunto inédito de estudos de caso, todos situados no subúrbio americano.

O professor Nathaniel ainda teve uma participação extra nas disciplinas AUP 5859 - Estúdio da Paisagem, da pós-graduação da FAUUSP, de responsabilidade do professor Paulo Pellegrino, e AUP 0667 - Análise Paisagístico-Ambiental, optativa da graduação, de responsabilidade do professor Euler Sandeville Jr. Nessa última ele proferiu, no dia 12 de setembro, dentro da série "Fórum da Paisagem", uma conferência para os alunos de graduação e para o público em geral.

\section{MESAS-REDONDAS}

No total de quatro, objetivaram trazer a opinião e as posturas de especialistas nacionais sobre os assuntos em pauta.

A primeira delas versou sobre a história do paisagismo e seus grupos de pesquisa no Brasil; trouxe representantes de dois dos mais importantes grupos de pesquisa nacionais: o de Recife (UFPE), coordenado pela professora Ana Rita Sá Carneiro, e o do Rio de Janeiro (UFRJ-EBA), chefiado pelo professor Carlos Terra, representado pela professora Jeanne Trindade, sendo a mesa dirigida pelo doutor Euler Sandeville Jr., da FAUUSP. Mostrar a história do paisagismo em uma mesaredonda teve como finalidade trazer à luz pesquisas consistentes de vanguarda desenvolvidas no país, para servir de exemplo e parâmetro para outros trabalhos.

A segunda mesa, uma indicação do VII ENEPEA, realizado em Belo Horizonte, teve como tema "Milton Santos e a Paisagem", como debatedores e expositores os professores Maria Angela F. Pereira Leite (FAUUSP) - uma das mais importantes discípulas de Milton Santos; Eugênio Queiroga (FAUUSP e PUCCamp), estudioso da obra santosiana; Miranda Magnoli, parceira e companheira de Milton nos anos 80, a qual nos relatou sobre seus estudos com o autor; foi coordenada pelo professor 
Ângelo Serpa (UFBA). Essa mesa foi fundamental como relato vivo do papel de Milton Santos no estabelecimento das bases conceituais do paisagismo nacional, fato esse desconhecido por muitos e, pela primeira vez, levado formalmente a público.

A terceira mesa, "Paisagismo e Participação", trouxe a temática da extensão ao primeiro plano, colocada em questão por especialistas como Luis Renato Bezerra Pequeno (UFCE), Catarina Lima (FAUUSP), Caio Boucinhas e Marta Enokibara (UNESP-Bauru).

A última mesa, "Ensino de Paisagismo", polêmica por tradição, trouxe o saudável embate entre diversos professores componentes da mesa e a platéia, especialmente entre os professores Fabio Mariz Gonçalves (FAUUSP) e Paulo Chiesa (UFPR). A questão do ensino foi levantada por Sonia Afonso (UFSC), Jonathas P. M. Silva (Anhembi- Morumbi), Vera Tângari (UFRJ) e Fábio Gonçalves, tendo sido discutidos conceitos e procedimentos de ensino diversos, tanto na escola pública como na privada.

Em seu conjunto as mesas-redondas serviram para colocar as diversas dimensões do ensino, pesquisa e extensão dentro do escopo do paisagismo nacional, mostrando a evolução do paisagismo nessas diversas vertentes.

\section{OFICINAS}

Tradicionalmente, no ENEPEA, são organizadas oficinas que procuram trazer um caráter prático a um evento essencialmente acadêmico. No caso do VIII ENEPEA, buscou-se a aplicação de oficinas eminentemente voltadas à prática do ensino e do projeto paisagístico.

As duas oficinas ("Ensino de Paisagismo - As Práticas Didáticas" e "Planejamento da Paisagem - Estudo para uma Infra-Estrutura Verde") foram desenvolvidas simultaneamente na tarde de sábado e congregaram a maioria dos professores, pesquisadores e alunos. A que tratou de ensino foi dividida em duas partes: a primeira, orientada por German Cruz, enfatizou a sensibilização espacial, e a segunda, elaborada com o professor Fabio Mariz Gonçalves, fez com que os professores participantes expusessem programas e exercícios de suas disciplinas em uma saudável troca de experiências didáticas.

A segunda oficina, desenvolvida por Paulo Pellegrino e Nathaniel Cormier, expôs um trabalho prático sobre um local real, no caso, os jardins da FAUUSP, para os quais foram propostas ações de caráter paisagístico e ambiental, a partir dos conceitos e práticas apresentados pelos professores em suas conferências.

\section{Grupos DE TRABALHO}

Foram montados dois grupos, cada um dedicado a focar uma das duas questões mais emergentes do paisagismo nacional, pelo menos no âmbito acadêmico, ou seja, o ensino, em especial seus conteúdos e inserção nas grades curriculares das diferentes escolas, e a pesquisa, tendo como foco a captação de recursos em agências financiadoras oficiais e a dificuldade cada vez maior de sua obtenção. 
Os dois grupos desenvolveram seus trabalhos paralelamente na tarde de sábado e, apesar da riqueza e da intensidade das discussões, poucos foram os resultados práticos obtidos devido ao pouco tempo reservado para tal. Acreditamos que, em novos eventos, essas temáticas devam ser objeto de mais tempo de reflexão e ocorrer em grupos que tenham seus trabalhos contínuos durante todo o evento.

O grupo de trabalho voltado à pesquisa contou com a presença da doutora Ivone Salgado, especialmente convidada para esclarecer pontos sobre a Fapesp e o CNPq. A discussão foi entrecortada por diversos depoimentos de pesquisadores e professores que colocaram suas inquietações e, principalmente, dificuldades. Ficou claro para nós estarmos em um momento de transição, no qual as pesquisas deixam de ser exclusivamente vinculadas à obtenção de titulação e passam, para muitos, a estarem unidas a procedimentos corriqueiros de trabalho, em especial nas universidades públicas, estaduais e federais. Desse modo, passa a ser um fato recorrente o surgimento, em diversas instituições, de grupos de pesquisa em paisagismo que, com o passar dos anos, devem crescer em número, produção e, portanto, em importância.

A participação nesse grupo dos professores Alina Santiago (UFSC), Vicente Barcellos (UnB) e Ana Rita Sá Carneiro (UFPE), especialmente convidados por sua larga experiência em pesquisa, foram elementos fundamentais nas discussões estabelecidas. Durante os debates ficou clara a desarticulação dos profissionais pesquisadores, tanto no tocante às linhas e grupos de pesquisa como para a captação de recursos. Aventou-se a constituição de uma associação de pesquisadores em paisagismo brasileiro, a estruturação de pesquisas em rede ou compartilhadas; mas de concreto, como posicionamento, nada se pode concluir de definitivo.

Como no primeiro grupo, conseguiu-se tão somente levantar questões, sem chegar-se a nenhuma postura clara que resultasse em indicações a serem encaminhadas para a plenária final. A questão principal, os conteúdos e os procedimentos didáticos, foram a tônica da discussão e ficou claro a todos a necessidade de desenvolver-se os conteúdos que podem preencher consistentemente as três categorias especificadas pelo MEC em suas diretrizes curriculares, para as quais cada curso e o currículo têm suas próprias interpretações, muitas vezes com grandes desvios em relação ao assunto.

\section{Comunicações}

Foi, com certeza, um dos pontos altos do evento, no qual se pôde observar maior consistência em termos de conteúdos e discussões.

Não foi intenção da Comissão de Seleção de Trabalhos separar as comunicações de acordo com a categoria de seu autor - pesquisador de doutorado, mestrado, iniciação científica ou outra qualquer -, valorizando-se a qualidade do texto. Essa foi uma medida que se mostrou acertada, pois o nível das apresentações foi alto e as discussões estabelecidas foram extremamente instigantes.

Todas as sessões extrapolaram seu tempo, especialmente por causa dos debates estabelecidos e não do prolongamento indevido dessa ou daquela apresentação. Poucas foram as ausências e estas foram ocupadas por debates. Em 


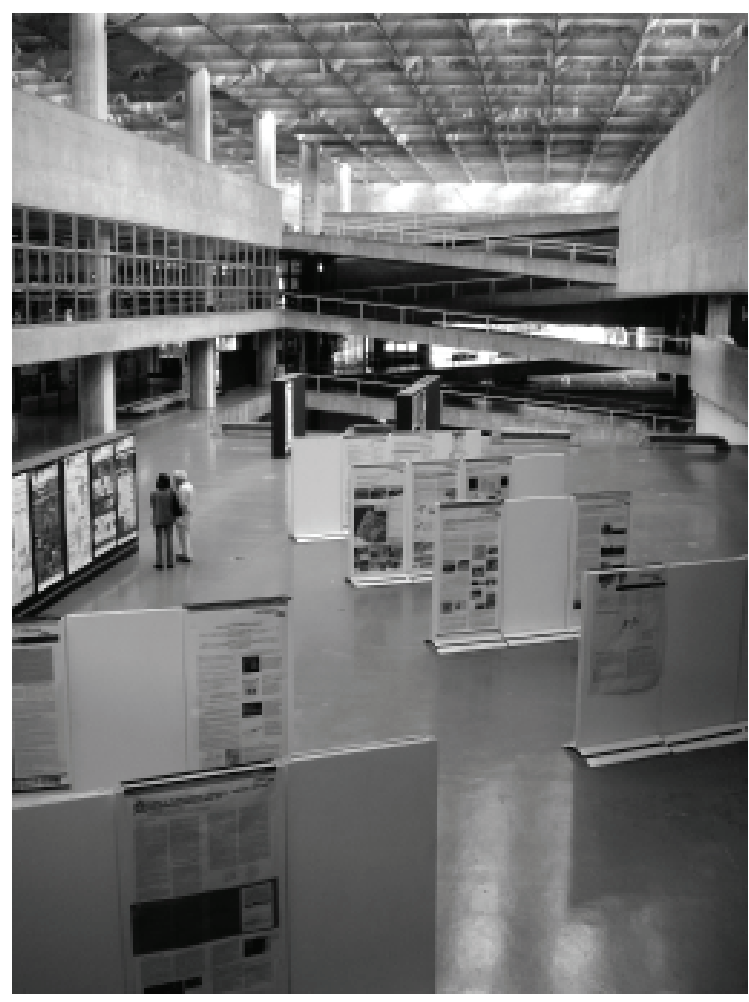

cada sessão estava encarregado um moderador, convidado pelo evento por sua capacidade de síntese e qualidade profissional, de controlar e encaminhar os debates.

\section{Painéis OU PÔSTERES}

Apesar da alta qualidade dos trabalhos encaminhados ao evento, muitos não foram selecionados para apresentação, porém foi indicada sua mostra na forma de painéis, os quais ficaram expostos durante todo o evento com a exposição de trabalhos de alunos.

Eram trabalhos vinculados à prática profissional, muitos dedicados a práticas didáticas e outros mais a expor resultados de atividades de extensão que, por seu caráter gráfico-descritivo, foram destinados a uma exposição visual e não-verbal.

Somente $5 \%$ dos painéis não foram enviados e o resultado foi uma exposição consistente e totalmente dentro dos objetivos do evento (ver Figura 3).
Figura 3:

Exposição de painéis no Salão Caramelo, FAUUSP Crédito: Acervo ENEPEA

\section{Concurso DE ALUnOS}

O ENEPEA, há algumas edições, tem se preocupado em valorizar as experiências didáticas, e o concurso de alunos tem sido um bom modo de alcançar-se tais objetivos.

Nessa edição, resolvemos instigar alunos e professores a desenvolver um assunto fundamental para o paisagismo urbano, e foi proposto como um dos temas do concurso o desenvolvimento de um sistema público de parques urbanos.

As respostas foram poucas, apenas cinco concorrentes nessa categoria, mas os trabalhos apresentados foram de excelente nível. O outro tema, para o qual se inscreveram 17 concorrentes, é tradicional, e focou-se na proposta de um parque urbano. Os vencedores foram os seguintes:

\section{Categoria Sistema de Parques}

1o lugar: Gestão das águas: Um sistema de parques ao longo das margens do rio Tietê/SP. Autora: Isabel Fleury Azevedo Costa; orientadores: Profa. Dra. Angélica B. Alvin e Prof. Dr. Valter Caldana. Universidade Presbiteriana Mackenzie;

2o lugar: Limeira: Sistema de espaços livres e urbanização. Autores: Camila Bellatini, Diego Brentegani, Ellen Cesonis, Gabriel de Andrade Fernandes, Jessila Fernanda de Araújo, Johnny Klemke Costa Pinho, Kim Ordonha Cirillo, Luciana Satiko Takaesu, Nathalia Vianna dos Santos, Renata Siqueira, Ricardo Cesarini Oliveto, Suzana Bilato Bozza, Wanderson Demétrius; orientador: Prof. Dr. Silvio Soares Macedo, FAUUSP; 
3o lugar: Jundiaí: Sistema de espaços livres públicos. Autores: Ary Henrique de Souza Neto, Augusto Pirani Ghilardi, Cristina Midori Rocha, Diogo Guermandi, Edson Tadashi Koza, Fabio Martini Pontes, Higor Rafael de Souza Carvalho, Laura Bensenõr Lotufo; orientador: Prof. Dr. Silvio Soares Macedo, FAUUSP.

\section{Categoria Parque Urbano}

10 lugar: O parque como elemento de conexão urbana - Córrego Água do Sobrado Bauru/SP. Autores: Ana Paula Costa Borbosa, Ligia Arriga Perassolli, Maria Fernanda Nóbrega dos Santos, Paula Navarro Peres de Freitas, Tarsila Miyazato; orientadora: Profa. Dra. Marta Enokibara, Unesp-Bauru;

2 Iugar: Várzea do Aricanduva: Redesenho zona leste de São Paulo. Autores: Anna Amorim, Cássia Itamoto, Ligia Medina, Marco Aurélia Grenier, Sueli Inoue, Vito Macchione; orientador: Prof. Dr. Fábio Mariz Gonçalves, FAUUSP;

3o lugar: Parque do Castelo: Estruturação urbana e requalificação da paisagem do fundo de vale Bauru/SP. Autores: Ana Beatriz Silva Lima, Érick Alexandro Tonin, Luciana Martin Barbosa, Rulian Nociti de Mendonça; orientadora: Profa. Dra. Marta Enokibara, Unesp-Bauru.

\section{Comentários FinAis}

Concluindo, podemos afirmar que o VIII ENEPEA foi mais maduro, no qual as questões foram propostas mais direta e objetivamente e com mais profundo estabelecimento de discussões.

Os trabalhos transcorreram dentro do programado, com ausência apenas de uns poucos autores, devidamente justificada, e com constante aporte de público, o qual participou do evento intensamente durante todos os dias. As sessões começavam sempre por volta das 9 horas e findavam entre $20 \mathrm{~h} 30$ e $21 \mathrm{~h} 30$, portanto uma média de 12 horas diárias de atividades dedicadas à discussão do paisagismo, de seu ensino e pesquisa.

O VIII ENEPEA foi, portanto, um sucesso - conseguimos trazer todos os nossos convidados, professores e pesquisadores e mantivemos uma boa afluência de público, oriundos das mais diversas partes do país. A cada edição a freqüência aumenta e a tendência é essa, apesar dos custos das viagens e das distâncias expressivas a percorrer-se.

Destacamos, ainda, que a execução do evento só foi possível devido ao apoio total da direção da FAUUSP, de seu então diretor Prof. Dr. Ricardo de Toledo e Silva, e da então vice-diretora Profa. Dra. Maria Ângela F. Pereira Leite; da gráfica da faculdade, que editou e imprimiu todos os elementos gráficos; da equipe de estudantes (monitores), fundamental na finalização e operacionalização do evento; e da secretária Francisca Batista de Souza, que estruturou, conosco e com a Comissão Organizadora, o encontro.

\section{Silvio Soares Macedo}

Arquiteto, professor titular de Paisagismo e Planejamento Ambiental na Faculdade de Arquitetura e Urbanismo da USP (FAUUSP). Criador e coordenador do Projeto Quadro do Paisagismo no Brasil (Quapá) e do Laboratório da Paisagem da FAUUSP. e-mail: ssmduck@usp.br 